\title{
La tercerización laboral como una forma para vulnerar derechos laborales
}

\author{
Mónica Marcela Cárdenas Álvarez ${ }^{*}$
}

Resumen. Las exigencias de la vida laboral del siglo xxI han ocasionado que las relaciones laborales tradicionales se vean trasegadas por la implementación de una figura jurídica denominada tercerización laboral. El presente artículo expone la implementación normativa que el Estado colombiano le ha otorgado a la forma laboral aludida, con el propósito de permitir un alcance en el campo del trabajo flexible con visos de productividad y utilidad, pero bajo un margen de condiciones. Posteriormente, se hace referencia a conceptos tanto de la doctrina, como de la jurisprudencia constitucional colombiana, además de lo referido por la Organización Internacional del Trabajo (OIT), a efectos de dar soporte a la teoría que ha mantenido esta última, la cual refiere a una orientación del uso correcto de la tercerización, pues de no ser así, se podrían estar disfrazando o encubriendo verdaderas relaciones de trabajo, que pueden implicar sanciones o multas por parte del inspector del trabajo y condenas por parte de los jueces laborales.

De manera que se arribe al lector a un concepto de equilibrio, es decir, que en materia de tercerización laboral, la búsqueda debe estar orientada hacia el justo balance de flexibilidad, estabilidad y seguridad, para adaptarse a los cambios estructurales y a la necesidad de implementar criterios que le otorguen confianza a los trabajadores, así como también, que en el desarrollo de este se genere una política de cambios con protección, en busca de medios para combinar los postulados a los que se ha hecho referencia.

Palabras claves: Flexibilización laboral, abuso, garantías laborales.

\footnotetext{
*Abogada de la Universidad de Ibagué, especialista en Derecho Administrativo y Derecho Laboral de la Universidad de Ibagué, especialista en Seguridad Social de la Universidad Externado de Colombia y candidata a magíster en Justicia y Tutela de los Derechos con énfasis en Derecho del Trabajo de la misma universidad. Correo electrónico: momarca@yahoo.com
} 
Las relaciones laborales como una de las formas esenciales con las que cuenta el hombre para garantizar su mínimo vital, han requerido de manera imperante la implementación y el reconocimiento de derechos laborales, a través de los cuales se puedan identificar las condiciones propias del vínculo contractual, el cual, conforme con estas disposiciones no puede actuar violando los derechos constitucionales, legales o prestacionales consagrados en la ley. Sin embargo, de acuerdo con la constante evolución que se ha generado en torno a las nuevas formas de trabajo, y debido a la implementación de la flexibilización en las relaciones laborales, se estableció una figura jurídica denominada tercerización laboral.

En principio, la relación laboral se circunscribe al contrato a término fijo, el cual, según el Decreto 2663 de 1950 en su artículo 46, "se debe realizar por escrito y no puede ser superior a dos años"; aquel fue modificado por el artículo 20 del Decreto 617 de 1954, que acogió las condiciones anteriores y agregó que no puede ser renovable de manera indefinida, ni puede durar menos de cuatro (4) meses. Del mismo modo, el Decreto 2351 de 2005 en su artículo 4 arguyó, que este contrato no puede ser inferior a un año, ni superior a tres, pero sostuvo las condiciones antes mencionadas sobre la renovación indefinida y la formalidad de ser escrito. Finalmente, se identifica lo estipulado en el artículo 46 del Código Sustantivo del Trabajo:

El contrato de trabajo a término fijo debe constar siempre por escrito y su duración no puede ser superior a tres años, pero es renovable indefinidamente.1. Si antes de la fecha del vencimiento del término estipulado, ninguna de las partes avisare por escrito a la otra su determinación de no prorrogar el contrato, con una antelación no inferior a treinta (30) días, este se entenderá renovado por un período igual al inicialmente pactado, y así sucesivamente.2. No obstante, si el término fijo es inferior a un (1) año, únicamente podrá prorrogarse sucesivamente el contrato hasta por tres (3) períodos iguales o inferiores, al cabo de los cuales el término de renovación no podrá ser inferior a un (1) año, y así sucesivamente. Parágrafo. En los contratos a término fijo inferior a un año, los trabajadores tendrán derecho al pago de vacaciones y prima de servicios en proporción al tiempo laborado cualquiera que este sea. (Código Sustantivo del Trabajo, Art. 46)

Ante lo expuesto, es necesario señalar que la figura de la tercerización laboral surge con la concepción de implementar servicios temporales en dichas relaciones laborales, es decir, en aquellas desarrolladas por contrato a término fijo, con el objetivo de ser la solución a ciertos problemas de las empresas. Lo 
anterior debido a que existe una gran cantidad de funciones necesarias, que no agregan valor relevante al objeto de la empresa, o porque existe una vacancia, entre otras circunstancias. En palabras de abogados especialistas en Derecho Laboral y con amplia participación en esta materia, se trata de una "actividad que consiste en la contratación de un sujeto especializado, independiente y autónomo, para la satisfacción de un servicio, a través del suministro de bienes o de la prestación de sus servicios a cambio de un precio determinado" (Bernal-Guerrero, 2017, p. 11). De manera que la vinculación que ofrece esta herramienta siempre será para proveer a un individuo ante una necesidad laboral, pero de forma temporal.

Por consiguiente, se debe recalcar que para el año 1935 mediante el Decreto 652 , se determinó que la materia a la que se alude era procedente para reemplazos de carácter transitorio como, por ejemplo, cuando algún trabajador se encontraba en vacaciones o ausente por enfermedad. Así mismo, ese criterio fue ampliado en el Decreto 2351 de 1965 en su artículo 4 inciso 2, al indicar que la temporalidad se implementaría para labores ocasionales y transitorias, como, por ejemplo, cuando se tratara de licencias, incrementos en la producción, transporte, ventas u otros actos análogos.

No obstante, a pesar de lo antes mencionado, para el año 1988 cuando se crea el Decreto 1433, se resaltó y se hizo la distinción de que la temporalidad no es del trabajador, sino del servicio prestado a un tercero para el desarrollo de sus actividades. Es así como los preceptos mencionados en precedencia constituyeron el inicio de las empresas de servicios temporales, las cuales fueron aludidas por primera vez, mediante la Ley 50 de 1990, considerando que se trata de entidades que contratan la prestación de servicios con terceros beneficiarios, para colaborar temporalmente en el desarrollo de las actividades de otra institución denominada usuaria, dejando claro que la primera siempre mantiene el carácter de empleador. Es decir, que con la expedición de esta nueva normatividad se estableció una distinción entre las relaciones jurídicas que surgen entre un trabajador dependiente y su empleador; el contratista independiente persona natural prestador de servicios y su contratante; y el trabajador en misión frente a su empleador y al usuario de sus servicios. De modo que se infiere que estas junto con otro grupo de reformas trajeron vientos de flexibilización del derecho del trabajo en el país.

Es necesario recalcar que, respecto de la procedencia de esta última figura, la normatividad señala que las empresas usuarias pueden contratar servicios con aquellas de servicios temporales, si cumplen con las condiciones estable- 
cidas en el artículo 77 de la antes mencionada, las mismas que consagra el Decreto 4369 del año 2006 en su artículo 6, así:

1. Cuando se trate de las labores ocasionales, accidentales o transitorias a que se refiere el artículo $6^{\circ}$ del Código Sustantivo del Trabajo.

2. Cuando se requiere reemplazar personal en vacaciones, en uso de licencia, en incapacidad por enfermedad o maternidad.

3. Para atender incrementos en la producción, el transporte, las ventas de productos o mercancías, los períodos estacionales de cosechas y en la prestación de servicios, por un término de seis (6) meses, prorrogable hasta por seis (6) meses más. (Decreto 4369, 2006)

Y se adicionó el siguiente parágrafo:

Si cumplido el plazo de seis (6) meses más la prórroga a que se refiere el presente artículo, la causa originaria del servicio específico objeto del contrato subsiste en la empresa usuaria, esta no podrá prorrogar el contrato ni celebrar uno nuevo con la misma o con diferente Empresa de Servicios Temporales, para la prestación de dicho servicio. (Decreto 4369, 2006)

Así las cosas, estas últimas condiciones de empresas de servicios temporales han sido las que han permeado la conceptualización de tercerización laboral y su posterior implementación, junto con el desarrollo legislativo que se le concedió a la Ley 1429 de 2010, a efectos de controlar la utilización de la misma, en la medida en que en varias oportunidades han sido mal utilizadas como, por ejemplo, en casos que fueron analizados por la alta corporación constitucional y que hoy son fruto de la jurisprudencia, los cuales se pueden observar en Sentencias T- 295 de 2008 y T-503 de 2015, entre otras. Así, mediante el artículo 63 de la mencionada norma, se limitó el ejercicio de la tercerización al señalar que el personal requerido para el desarrollo de las actividades misionales permanentes en una empresa o institución - pública o privada - no podrá estar vinculado: i) por Cooperativas de Trabajo Asociado o ii) bajo ninguna modalidad que afecte los derechos constitucionales, legales $\mathrm{y}$ prestacionales consagrados en las normas laborales vigentes.

En suma, debe quedar claro que la representación de la tercerización laboral es legal y se encuentra aceptada por los instrumentos descritos anteriormente, con armonía de su fuente principal. Estos son los artículos 34 del Código Sustantivo del Trabajo (contratistas independientes) y el artículo 968 del Código de Comercio (contrato de suministro). El problema radica en el uso; por lo mismo, el legislador se ha dado a la tarea de expedir normas (D. 2025 de 2011; 
D. 2790 de 2013; D. 583 de 2016 y Resolución 5670 de 2017) para atacar la tercerización laboral, aquella que se efectúa con el fin de reducir costos en perjuicio de los derechos y garantías laborales, como un abuso en la figura por parte de algunos contratantes.

Sin embargo, pese a existir estas reglas de procedencia, su implementación ha quedado en un espectro anarquista en el manejo del concepto de tercerización, puesto que en la realidad la implementación de este modelo por parte de algunas empresas ha estado abanderado por el desconocimiento del criterio de temporalidad, de tal manera que una vez vencidos los presupuestos por los cuales implementaron la tercerización laboral, los trabajadores continúan ejerciendo la misma actividad laboral, situación que en esencia cambiaría las condiciones desde un criterio ampliamente garantista, pero que en la vida real se disfraza y se mantiene.

En efecto, esta condición se torna en un abuso de la temporalidad establecida desde los mismos inicios de la creación de esta figura y, en razón a ello, se olvidan los lineamientos impartidos por el legislador como la temporalidad, la transitoriedad y lo ocasional del servicio. De tal manera que con dicho desconocimiento de la legislación y manteniendo a un trabajador que fue contratado en condiciones de temporalidad, que ejerce labores que se tergiversan de la razón por la que fuere querido inicialmente, se sesga el límite o la frontera entre una y otra clase de trabajo y se torna difusa.

Es por eso que esta situación que ha permitido el surgimiento de relaciones de trabajo encubiertas, disfrazadas, ambiguas y triangulares, en perjuicio de los intereses de los trabajadores, de los empleadores, del Estado y la sociedad, constituye un abuso que no debe tolerarse porque permea esas garantías básicas laborales de los trabajadores. Ahora, cuando se hace mal uso de la tercerización, se constituye en una práctica de carácter ilegal.

A propósito de la tesis que se plantea, la OIT concluyó lo siguiente en la Resolución relativa a la relación de trabajo, adoptada en la $91 .{ }^{a}$ Conferencia General de 2003:

Advierte la oIT que no es su propósito combatir otras formas de relaciones jurídicas distintas a la relación de trabajo; sino todo lo contrario: que todos los actores del mercado de trabajo tengan acceso al uso de una amplia gama de acuerdos por medio de los cuales un trabajador realiza o presta servicios a un empleador o un empresario, pero dentro de un uso correcto de las distintas formas jurídicas laborales y no laborales. (огт, 2003) 
Por su parte, la RedLat (2010) lo analiza en un trabajo a partir del cual concluye que estas formas de contratación:

Ha producido efectos sobre la situación de los trabajadores que, por su profundidad y gravedad, se han llegado a considerar, conjuntamente con la pobreza, como la 'cuestión social' de nuestra época. Han venido deteriorando prácticamente todas las dimensiones o componentes básicos, comúnmente señalados, del llamado trabajo decente. Pero afectan en especial aquellas relacionadas con el desempleo, la remuneración, estabilidad y discriminación en el trabajo, la seguridad social, y el derecho de asociación y acción colectiva, debilitando por lo demás la organización sindical en razón en especial de la segmentación de la clase trabajadora y su identidad, incorporando, además, graves riesgos a estos colectivos de trabajadores, como los siguientes riesgos: de deslaboralización o informalización laboral, de bajos ingresos laborales, de desprotección social, de discriminación laboral, de insolvencia del empleador formal, de desempleo recurrente, de pérdida de derechos colectivos. (RedLat, 2010, p. 26)

En este sentido, conviene subrayar que el papel que representa el Estado es fundamental, teniendo en cuenta que, para encontrar soluciones al abuso de temporalidad en la tercerización laboral, este debe jugar un rol de primer orden al dirimir las controversias que se suscitan entre la siempre pretendida ampliación de la flexibilidad laboral. De ahí que como lo señala Mario Ackerman, catedrático de Derecho del Trabajo y de la Seguridad Social y director del Departamento de Derecho del Trabajo y de la Seguridad Social, de la Facultad de Derecho de la Universidad de Buenos Aires (Argentina)(2001)en ponencia presentada en el V Congreso Regional Americano en Lima:

Venimos de un triángulo virtuoso de protección donde se deben realizar estrategias que permitan establecer condiciones dirigidas a privilegiar la economía, y además a garantizar la protección y brindar la seguridad jurídica que reclaman los trabajadores en estas condiciones. Puesto que la mala utilización de esta figura puede constituir una tercerización ilegal.

Habría que decir también que, como se refirió con antelación en Colombia, se ha venido dando tratamiento a este tema por medio de la Ley 1429 de 2010, la cual a través de su artículo 63 ha precisado y aclarado el alcance de esta figura, en lo referente a la contratación de personal, a través de otras modalidades de vinculación, como la tercerización laboral. En ese orden de ideas, precisa que esta es ilegal cuando en una institución o empresa pública o privada coincidan dos elementos:1) se vincule personal para el desarrollo de actividades misionales permanentes a través de un proveedor (instituciones, 
empresas, personas naturales o jurídicas u otras modalidades contractuales, sociales o cooperativas, públicas o privadas), es decir, por cooperativas de trabajo asociado o 2) se vinculen personas de una forma que afecte los derechos constitucionales, legales y prestacionales consagrados en las normas laborales vigentes.

Simultáneamente, lo ha hecho el Decreto 0583 del 8 de abril de 2016 emitido por el Ministerio de Trabajo y a través del cual se adiciona el Decreto Único Reglamentario del Sector de Trabajo № 1072 de 2015 cuando define nueve elementos que permiten asegurar que la intermediación es ilegal, toda vez que en él se integran aspectos que deben ser tenidos en cuenta en el ejercicio de la Inspección, Vigilancia y Control sobre los procesos de tercerización y los derechos laborales que deben garantizarse en estos:

1. Que se contrató al proveedor para hacer las mismas o sustancialmente las mismas labores que se realizaban para el beneficiario y los trabajadores no fueron expresamente informados por escrito. 2. Que el proveedor no tenga capacidad financiera acorde con el servicio u obra que contrata. 3. Que el proveedor no tenga capacidad, de carácter administrativo o financiero, para el pago de salarios, prestaciones e indemnizaciones de sus trabajadores. 4. Que el proveedor no tenga la autonomía en el uso de los medios de producción, ni en la ejecución de los procesos o subprocesos que le sean contratados. 5. Que el proveedor no imparta las instrucciones de tiempo, modo y lugar para la ejecución de la labor de sus trabajadores, o no ejerza frente a ellos la potestad reglamentaria y disciplinaria, sin perjuicio de otras actividades de coordinación que sean necesarias por parte del beneficiario para el adecuado desarrollo del objeto del contrato. 6. Que el proveedor no realice el pago de los salarios y prestaciones legales y extralegales oportunamente o no cumpla con las obligaciones en materia de seguridad social. 7. Que el beneficiario fraccione o divida, mediante uno o más proveedores, a trabajadores afiliados a un sindicato inscrito o a trabajadores que hayan realizado la asamblea de constitución o la reunión inicial de constitución de un sindicato. 8. Que a los trabajadores que trabajaban para el beneficiario no se les otorguen por parte del proveedor iguales derechos a los que tenían cuando estaban contratados directamente por el beneficiario para el desarrollo de las mismas o sustancialmente las mismas actividades. 9. Que el beneficiario y el proveedor incurran en conductas violatorias de las normas laborales vigentes en la celebración o ejecución de la figura que los une. (Ministerio del Trabajo, 2016, p. 4 y 5)

En pocas palabras, con los presupuestos antes mencionados, aunque el legislador tomó medidas respecto de la mala utilización de la tercerización laboral e indicó los casos en los cuales se puede identificar una indebida utilización 
de esta figura es pertinente resaltar que, lo hizo de manera generalizada por lo que en el mismo existen circunstancias que en nada protege a los trabajadores. Un ejemplo de este argumento se circunscribe en el numeral 4, donde señala que "el proveedor no tenga la autonomía en el uso de los medios de producción y desintegra las condiciones por las cuales se ha implementado dicha labor" (Ministerio del Trabajo, 2016, p. 4). De manera puntual nos referimos a que en el caso de una persona que es contratada por aumento en la productividad de la empresa y esta se mantiene en el tiempo, el empleador siempre va a tener la autonomía en el uso de esos medios de producción, y además no se trata solo de un trabajo coordinado como se pretende esbozar en dicho postulado, sino en una labor que amerita claramente subordinación, por lo que se pone en tela de juicio la conducencia, pertinencia y utilidad que le pueda dar esta disposición a la materia a la que se ha hecho referencia.

Así las cosas, es probable que las condiciones de violación a la ley, pueden persistir en el tiempo, hasta tanto el legislador no establezca condiciones específicas y no tan generalizadas como las antes vistas. En dichas condiciones no se percibe algún cambio contundente como lo debe ser la protección del artículo 53 de la Carta Política en cuanto a los mínimos laborales y el principio in dubio pro operario.

Habría que decir también que a pesar de que en la actualidad la Resolución 5670 de 2017 por medio de la cual se establecen lineamientos respecto de la Inspección, Vigilancia y Control que se adelante frente al contenido de los artículos 74 de la Ley 1753 de 2015 y 63 de la Ley 1429 de 2010, así como de sus Decretos Reglamentarios, se perfila como una nueva herramienta por parte del Ministerio del Trabajo para atacar el uso indebido de la tercerización laboral. La misma no hace ningún cambio, sino que tiende a emitir pronunciamientos desfasados del poder reglamentario que se le ha permitido.

Lo anterior, se presenta en la medida en que termina regulando aspectos que no hacen parte de la Ley 1429 de 2010 (intermediación laboral) y se mantiene en ese espectro censurado de definiciones que con anterioridad ya habían sido sancionadas por las Altas Cortes, en especial por el Consejo de Estado, mediante auto del 15 de marzo del presente año, el cual resolvió suspender provisionalmente los efectos de los numerales 4 y 6 del artículo 2.2.3.2.1 del Decreto Único Reglamentario del Sector del Trabajo, que corresponden a las definiciones de beneficiario y proveedor, de tercerización laboral y tercerización laboral ilegal del Decreto 0583 de 2016. 
De acuerdo con lo expuesto, encuentra la ponente que los enunciados normativos demandados desbordan materialmente el contenido esencial del artículo 63 de la Ley 1429 de 2010, el cual hace referencia a la prohibición de contratar personal a través de cooperativas de trabajo asociado, ni bajo ninguna otra forma de vinculación de intermediación laboral, para desarrollar actividades misionales permanentes en los sectores público y privado, mientras que la norma reglamentaria, regula aspectos relacionados con la tercerización laboral, dentro de la cual ubica todos los mecanismos legales de intermediación laboral, aspectos estos que no están comprendidos en la referida ley. (Consejo de Estado-Sala de lo Contencioso Administrativo, Sentencia Radicado No. 11001032500020160048500 de 2017)

Lo dicho hasta aquí supone que el término tercerización se ha generalizado para referirse a la contratación de servicios, e involucra la vinculación indirecta de trabajadores. En este sentido, fragmenta su mano de obra, disminuye sus condiciones laborales y debilita y desestructura sus derechos colectivos. Habría que decir también que esta situación, además de aumentar la flexibilidad del mercado de trabajo, ha contribuido a que no esté clara la situación laboral de un creciente número de trabajadores, y que, consecuentemente, queden excluidos del ámbito de la protección, normalmente asociada con una relación de trabajo.

Así que, en definitiva, la manera más propensa para evitar el abuso de la tercerización laboral en detrimento del trabajador lo constituye su asimilación al trabajador dependiente. Esto equivaldrá a otorgarle aplicación extensiva, al menos en forma parcial, al Código Sustantivo del Trabajo. De tal manera que una vez se logre identificar que no cumple con los requisitos establecidos en el Decreto 4369 de 2006 y el artículo 63 de la Ley 1429 de 2010, se termine la prestación del servicio o se reconozca el principio de primacía de la realidad sobre las formalidades, tarea que está bajo la competencia del ente encargado de ejercer vigilancia y control, en este caso, del Ministerio del Trabajo.

De ahí que el legislador debe asegurarse de generar un equilibrio entre flexibilidad y protección, para evitar efectos perversos sobre la economía y el trabajador. De esta manera, estaría reforzando el campo de acción de la seguridad social, pues la utilización de esta figura en muchas ocasiones propende por disminuir el reconocimiento de derechos laborales hacia el trabajador, como es el caso de los derechos sindicales, etc.

Es por esto que, la tercerización laboral como figura jurídica en Colombia requiere un uso correcto, porque de no ser así, se estarían disfrazando o encubriendo las relaciones de trabajo. De modo que, si hacemos un esfuerzo 
por darle a la tercerización su verdadera dimensión, ya se trate de bienes, o de servicios, o de recurso humano, daremos un gran paso para la formalización, entendida como el cabal cumplimiento de las garantías laborales, independiente del tipo de vinculación.

Por lo tanto, la tercerización laboral en sí misma no es ilegal, a diferencia de ello, la misma ort ha señalado que dinamiza la economía del país, al mismo tiempo que potencializa las industrias y disminuye la informalidad laboral. Para simplificar, si bien es cierto que por regla general se debe implementar la contratación laboral directa, también lo es que el suministro de bienes y servicios de las empresas temporales es una alternativa cuando se trata de temporalidad laboral. De ahí que, si la tercerización no tiene la finalidad de suplir una necesidad de bienes y servicios de la empresa, sino de la persona individualmente considerada, estamos ante una violación de la ley laboral.

Así que en este artículo no se niega que también la flexibilidad es necesaria y beneficiosa, pero el debate sobre el tema nos ha hecho creer que ella y los ajustes veloces entre los trabajos y las empresas son la única respuesta, a pesar de que también existe la posibilidad que se efectúen estas actividades dentro de los trabajos o las empresas, mientras se mantiene la relación de empleo con todas las gabelas reconocidas por el Constituyente. Máxime cuando vemos ajustes que son favorecidos por políticas de mercado de trabajo. Es por esto que hoy la búsqueda debe estar orientada hacia el justo balance de flexibilidad, estabilidad y seguridad, para adaptarse a los cambios estructurales y a la necesidad de generar condiciones pro para los trabajadores.

En conclusión, es indispensable reconocer no solo que la implementación de la tercerización laboral en las relaciones de trabajo permite un alcance mayor a la productividad y a la contratación, en particular, en los mercados de trabajo sujetos al impacto de la creciente globalización, sino también lo es que se debe dar un uso correcto a las formas jurídicas laborales y no laborales y este debe estar bajo la vista del Estado y de sus diferentes organismos de protección laboral, para no incurrir en prácticas que contribuyan al detrimento de garantías laborales de los trabajadores.

Lo más importante es que para alcanzar ese objetivo es necesario que se implemente una política de equidad entre las nuevas actividades legislativas en el ámbito laboral y el desarrollo de la economía globalizada, en busca de medios para combinar flexibilidad y seguridad, puesto que de ser así se alcanzaría el componente que opera en armonía con la concepción de trabajo decente brindada por la oIT: 
Trabajo productivo con remuneración justa, seguridad en el lugar de trabajo y protección social para el trabajador y su familia, mejores perspectivas para el desarrollo personal y social, libertad para que manifiesten sus preocupaciones, se organicen y participen en la toma de decisiones que afectan a sus vidas, así como la igualdad de oportunidades y de trato para mujeres y hombres.(OIT, 2007)

En definitiva, lo anterior permitiría lograr el ejercicio efectivo de buenas prácticas del derecho laboral, aspecto en el cual están comprometidos todos los actores de la sociedad. Así por ejemplo el Estado, de conformidad con lo establecido en (Corte Constitucional, Sentencia C-614 de2009); los empresarios, en el uso correcto de la tercerización, y los trabajadores en el respecto que arriben a su labor.

\section{Referencias}

Ackerman, M. (septiembre, 2001). Reflexiones en torno de la dependencia laboral y la descentralización empresaria de cara a la Legislación y la Jurisprudencia argentinas. El Derecho del Trabajo ante las nuevas formas del Trabajo. V Congreso Regional Americano, Lima, Perú.

Bernal García, F., Guerrero Orbe, D., \& Godoy Córdoba. (mayo-junio, 2017). Resolución 5670 de 2016. ¿Reglas claras en materia de tercerización laboral?, Legis, Bogotá, 2017. Revista Actualidad laboral, (201), 11-16.

Código Sustantivo del Trabajo. (2016). Artículo 46. Editorial Legis. Primera edición. Bogotá.

Decreto 0583. (2016). Adición al Decreto Único Reglamentario del Sector del Trabajo $\mathrm{N}^{\mathrm{a}} 1072$ de 2015. P. 4 y 5.

OIT. (2003). Resolución relativa a la igualdad de remuneración. 91a Conferencia General. Ginebra.

RedLat. (2010). Estado del Trabajo Decente en 7 países de América Latina, incluida Colombia. p. 26.

Sentencia T-295 (2008). Corte Constitucional de Colombia. Magistrado ponente: Clara Inés Vargas Hernández.

Sentencia C-614 (2009). Corte Constitucional de Colombia. Magistrado ponente: Jorge Ignacio Pretelt Chaljub.

Sentencia T-503(2015). Corte Constitucional de Colombia. Magistrado ponente:María Victoria Calle Correa.

Sentencia (2017, marzo 15). Consejo de Estado-Sala de lo Contencioso Administrativo.Sección Segunda. Radicado N.11001032500020160048500. Consejera ponente: Sandra Lisset Ibarra Vélez. 


\section{Bibliografía recomendada}

González, J., García, N., \& Puig, J. (2010). Situación de la subcontratación en América Latina y perspectivas para su regulación. Medellín, Colombia: Escuela Nacional Sindical.

López, D. (2008). Subcontratación y conflictos laborales: Un creciente descontento en el trabajo.Santiago de Chile, Chile: Ediciones Facultad de Ciencias Económicas y Administrativas Universidad Central.

Torregroza Sánchez, A. (2013). Vademécum de Jurisprudencia. Bogotá: Librería Ibáñez. 